\title{
A study on the incidence of tuberculosis in Narail district of Bangladesh
}

\author{
MS Mallick
}

\begin{abstract}
The aim of this descriptive type of study on diagnosed tuberculosis (TB) cases was to evaluate the incidence of TB in Narail district to have a situational analysis with the achievement of National TB Control Program. Related data were collected from the Civil Surgeon Office, Narail district. The data of 3 upazilas- Narail Sadar, Kalia, and Lohagora were used. The study period was from January 1, 2016 to December 31, 2016. The overall TB case rate was 156.6 per 100000 population and separately 170.9 per 100000 population in Narail Sadar, 142.2 per 100000 population in Kalia and 156.6 per 100000 population in Lohagora. Of the cases, $56.4 \%$ were male and $43.6 \%$ female. Overall, $89.7 \%$ of the TB cases had pulmonary TB and $10.3 \%$ had extra-pulmonary TB. The population with higher age had higher proportion having TB. The highest number of patients were referred for diagnosis by sastha sebika (nurse) and non-government field staff. The TB incidence in Narail district was considered to be lower than the National situation. However, it seems that TB will remain as a continuous concern for many years in future for the country as well as Narail district. The activities of National TB Control Program of the Government of Bangladesh needs to be strengthened further to combat TB in Bangladesh
\end{abstract}

Keywords: tuberculosis, incidence, Narail district, Bangladesh.

\section{Introduction}

Tuberculosis (TB) is one of the oldest disease and a major cause of death worldwide. If properly treated, virtually all TB cases are curable. In 2009, more than 9.4 million new TB cases were diagnosed and 1.7 million patients died due to TB globally. ${ }^{1}$ In 2010, global estimated new TB cases were 8.8 million and death due to TB were 1.5 million. $^{2}$ In 2013 , global estimated new TB cases were 9 million and death due to TB were 1.5 million. ${ }^{1}$ In 2014, 9.6 million people were infected with TB worldwide and 1.5 million died from the disease. ${ }^{3}$ It has also been mentioned that over $95.0 \%$ of TB deaths occur in low- and middle-income countries.

The South-East Asia region accounts for a disproportionately high number of global TB cases and Bangladesh is one of 22 'high TB-burden' countries. ${ }^{3}$ In 2014, there were 187005 new cases of TB in Bangladesh and it was the leading cause of death, accounting for 81000 fatalities. $^{3}$ Ending the TB epidemic by 2030 is one of the health targets of the newly adopted Sustainable Development Goals. World Health Organization has set a target for a $95.0 \%$ reduction in deaths and a $90.0 \%$ reduction in TB incidence by $2035 .{ }^{3}$ In Bangladesh, 3 lakh of new TB patients were diagnosed and 70000 died due to TB every year and among all TB patients $80.0 \%$ were pulmonary and $20.0 \%$ were extrapulmonary. ${ }^{4}$ The Government of Bangladesh has given strong emphasis on TB control program; BRAC has been playing an important role in National TB Control Program in 
Bangladesh since 1992.

The program is also active in Narail district of Bangladesh. The aim of this descriptive type of study on diagnosed TB cases was to evaluate the incidence of TB in Narail district to have a situational analysis with the achievement of National TB Control Program.

\section{Materials and Method}

The descriptive type of study on diagnosed TB cases was conducted using data from 3 upazilas of Narail district- Narail Sadar, Kalia, and Lohagora from January 1, 2016 to December 31, 2016. The total population of study area of Narail district is 868000 as of June 2017 (Narail Sadar- 306000, Kalia306000 and Lohagora- 256000). The related data were collected from Civil Surgeon Office, Narail. The data were checked and verified after collection. Data were processed manually and the compilation and analysis were done using a calculator.

\section{Results}

Table 1 shows the rate of TB cases. The overall rate was 156.6 per 100000 population and separately 170.9 per 100000 population in Narail Sadar, 142.2 per 100000 population in Kalia and 156.6 per 100000 population in Lohagora.
Table 2 shows the distribution of TB cases according to the gender. Overall, $56.4 \%$ of the TB cases were male and $43.6 \%$ female.

Table 3 shows the distribution of TB cases according to the disease location. Overall, $89.7 \%$ of the TB cases had pulmonary TB and $10.3 \%$ had extra-pulmonary TB.

Table 4 shows the distribution of TB cases according to the age of the population. The population with higher age had higher proportion having TB.

Table 5 shows the distribution of TB cases according to referrers through whom the diagnosis of TB was confirmed. The highest number of patients were referred for diagnosis by sastha sebika (nurse) and nongovernment field staff.

\section{Discussion}

A total number of diagnosed TB cases were 1359. The overall TB case rate was 156.6 per 100000 population and separately 170.9 per 100000 population in Narail Sadar, 142.2 per 100000 population in Kalia and 156.6 per 100000 population in Lohagora. Of the cases, $56.4 \%$ were male and $43.6 \%$ female. Overall, $89.7 \%$ of the TB cases had pulmonary TB and $10.3 \%$ had extra-pulmonary TB. The population with higher age had higher

Table 1. Rate of TB cases according to place

\begin{tabular}{lrrr}
\hline Upazila & Population & TB cases & $\begin{array}{r}\text { Rate per } \mathbf{1 0 0 0 0 0} \\
\text { population }\end{array}$ \\
\hline Narail Sadar & 306000 & 523 & 170.9 \\
Kalia & 306000 & 435 & 142.2 \\
Lohagora & 256000 & 401 & 156.6 \\
\hline Total & $\mathbf{8 6 8 0 0 0}$ & $\mathbf{1 3 5 9}$ & $\mathbf{1 5 6 . 6}$
\end{tabular}

Data are presented as number or rate per 100000 population.

Table 2. Distribution of TB cases according to gender, number $=1359$

\begin{tabular}{lrr}
\hline Upazila & Male & Female \\
\hline Narail Sadar & $314(60.0)$ & $209(40.0)$ \\
Kalia & $229(52.6)$ & $206(47.4)$ \\
Lohagora & $224(55.9)$ & $177(44.1)$ \\
\hline Total & $767(56.4)$ & $592(43.6)$ \\
\hline
\end{tabular}

Data are presented as number (\%). 
Table 3. Distribution of TB cases and disease location, number $=1359$

\begin{tabular}{lrr}
\hline Upazila & Pulmonary TB & Extra-pulmonary TB \\
\hline Narail Sadar & $470(89.9)$ & $53(10.1)$ \\
Kalia & $388(89.2)$ & $47(10.8)$ \\
Lohagora & $361(90.0)$ & $40(10.0)$ \\
\hline Total & $\mathbf{1 2 1 9 ( 8 9 . 7 )}$ & $\mathbf{1 4 0 ( 1 0 . 3 )}$ \\
\hline
\end{tabular}

Data are presented as number (\%).

Table 4. Distribution of TB cases according to age of the patients, number $=1359$

\begin{tabular}{lrr}
\hline Age in years & Number & $\%$ \\
\hline$\leq 5$ & 1 & 0.1 \\
$>5-\leq 15$ & 46 & 3.3 \\
$>15-\leq 25$ & 89 & 6.6 \\
$>25-\leq 35$ & 149 & 11.0 \\
$>35-\leq 45$ & 214 & 15.8 \\
$>45-\leq 55$ & 295 & 21.7 \\
$>55-\leq 65$ & 290 & 21.3 \\
$>65$ & 275 & 20.2 \\
\hline Total & $\mathbf{1 3 9 5}$ & $\mathbf{1 0 0 . 0}$ \\
\hline
\end{tabular}

Data are presented as number or \%.

Table 5. Distribution of TB cases according to referrers, number $=1359$

\begin{tabular}{lrrrrrrrrrr}
\hline Upazila & $\begin{array}{r}\text { GPPI } \\
\text { NGPP }\end{array}$ & GFS & $\begin{array}{r}\text { SSI } \\
\text { NGFS }\end{array}$ & VD & CV & GH & PH & CHCP & $\begin{array}{r}\text { TB } \\
\text { Oatient }\end{array}$ \\
\hline Narail Sadar & 54 & 7 & 357 & 4 & 6 & 59 & 2 & 5 & 5 & 24 \\
Kalia & 115 & 5 & 284 & 1 & 0 & 28 & 1 & 0 & 0 & 1 \\
Lohagora & 33 & 5 & 310 & 2 & 0 & 39 & 6 & 2 & 1 & 3 \\
\hline Total & $\mathbf{2 0 2}$ & $\mathbf{1 7}$ & $\mathbf{9 5 1}$ & $\mathbf{7}$ & $\mathbf{6}$ & $\mathbf{1 2 6}$ & $\mathbf{9}$ & $\mathbf{7}$ & $\mathbf{6}$ & $\mathbf{2 8}$ \\
\hline
\end{tabular}

Data are presented as number. GPP, graduate private practitioner; NGPP, non-graduate private practitioner; GFS, government field staff; SS, sastha sebika (nurse); NGFS, non-government field staff; VD, village doctor; CV, community volunteer; $\mathrm{GH}$, government hospital; $\mathrm{PH}$, private hospital; $\mathrm{CHCP}$, community health care provider.

proportion having TB. The highest number of patients were referred for diagnosis by sastha sebika (nurse) and non-government field staff. The diagnosis was made on the basis of detection of mycobacteria from the specimens of sputum, ascitic fluid, pleural fluid, pus from chronic discharging sinuses, chest X-ray, FNAC of lymph nodes, Tuberculin test \& ESR. The National TB incidence rate in 2016 was 221 per 100000 population. ${ }^{5}$ Thus, the TB incidence in Narail district was considered to be lower than the National situation. However, it seems that TB will remain as a continuous concern for future for the country as well as Narail district. The activities of National TB Control Program of the Government of Bangladesh needs to be strengthened to combat TB in Bangladesh.

Total diagnosed TB cases under the age of 15 years were $3.4 \%$ (pulmonary and extrapulmonary). So, the detection rate of child tuberculosis was very low. The burden of TB in children is unknown because of the lack of child-friendly diagnostic tools and inadequate surveillance and reporting of TB cases. BCG, 
the only licensed TB vaccine has limited efficacy against the most common forms of childhood TB and its efficacy is of limited duration. ${ }^{6}$ Most public health programs have limited capacity to meet the demand for care and high-quality services for childhood TB.

In case of the adult, the total number of diagnosed TB cases (all forms) were higher in males than females (male : female $=1.3: 1$ ). The incidence of TB over 40 years was also higher in males than females which may be due to smoking, concurrent diseases, and many other environmental factors. In case of suspected TB cases of young and adult females, some conservative family does not come for a medical check-up for fear of social stigma. ${ }^{7}$ So, detection of some percentage of female TB cases remains undiagnosed.

All the patients were referred by graduate private practitioner (GPP), non-graduate private practitioner, government field staff, sastha sebika (nurse) (SS), non-government field staff (NGFS), village doctor, community volunteer, government hospital $(\mathrm{GH})$, private hospital, and community healthcare provider for TB diagnosis and the TB patients were then treated by them. Most of the patients were referred by SS, NGFS, GPP \& GH.

The number of TB cases in Bangladesh including Narail district being reported has increased and a treatment success rate of 93\% has been achieved among all new and relapsed cases. ${ }^{3}$ The multi-drug resistant TB treatment success rate is also high at $73 \%{ }^{3}$

A greater number of automated diagnostic machines that can determine TB infection from a sample in a short period of time are in use. However, Bangladesh faces challenges in achieving universal access to TB prevention and care services because of poor access to good quality diagnostic services, an inadequate system for screening and lack of sustainable funding for staffing. Lack of engagement of private health practitioners in the implementation of the government's mandatory case notification system is also a problem. It seems that TB will remain as a continuous concern for many years in future for the country as well as Narail district. The activities of National TB Control Program of the Government of Bangladesh needs to be strengthened further and the general public needs to be better informed about TB and its treatment to combat TB in Bangladesh.

\section{References}

1. Harrison's Principles of Internal Medicine, 18th ed. McGraw Hill: New Delhi, 2012.

2. Davidson's Principles \& Practice of Medicine; 22nd ed. Churchill Livingstone: Elsevier, 2014.

3. World Health Organization. WORLD TB DAY 2016: Bangladesh continues its battle against the disease. Available from http://www.searo.who.int/bangladesh /world-tb-day-2016/en/ (Accessed on December 15, 2017).

4. National TB Control Program, DG Health Services \& Ministry of Health \& Family Welfare, Bangladesh. Bulletin-June-2007.

5. Bangladesh. Tuberculosis profile. Available from https://extranet.who.int/sree/ Reports?op=Replet\&name $=/ \mathrm{WHO} H \mathrm{HQ} R$ eports/G2/PROD/EXT/TBCountryProfile\& ISO2=BD\&outtype $=p d f \quad$ (Accessed on December 15, 2017).

6. Hokey DA, Ginsberg A. The current state of tuberculosis vaccines. Hum Vaccin Immunother 2013;9(10):2142-6.

7. Johansson E, Long NH, Diwan VK, Winkvist A. Gender and tuberculosis control: perspectives on health seeking behaviour among men and women in Vietnam. Health Policy 2000;52(1):33-51.

\section{Suggestion for citation of the above:}

